\title{
Characterization of Southwestern Nigeria River Sand for foundry use
}

\author{
B.V. Omidiji ${ }^{*}$ H.A. Owolabi, D.A. Adetan \\ Department of Mechanical Engineering, Obafemi Awolowo University, Ile-Ife, Nigeria
}

(Received 5 May 2020, accepted 11 July 2020)

Doi: https://doi.org/10.36224/ijes.130201

\begin{abstract}
The greater number of castings produced globally are made by using sand casting techniques that utilize sand as major moulding material. This paper characterizes Isasa River sand based on its physical and chemical properties with the aid of Tandem pelletron electrostatic accelerator, trinocular microscope, mechanical sieve shaker, and box furnace, for Foundry application. Results obtained revealed that the River sand has moisture content of 4.30\%, clay content of $2.22 \%$, grain fineness number (GFN) of 49 , Silica (SiO2) content of $93 \%$, and sintering point of $1400^{\circ} \mathrm{C}$. The River sand is a 4-screen sand, having angular grains with medium sphericity. Isasa River sand will be suitable for casting of gray iron and non-ferrous metals, with the addition of binding agent in suitable proportion.
\end{abstract}

Keywords: Sand, Casting, Foundry, Properties, Metals.

\section{Introduction}

Foundry can be defined as a workshop where such production operations as moulding, melting of metals and alloys, metal pouring to mould cavities, solidification, shake out and fettling of castings are carried out. The greater part of the Foundry industry activities consists of castings made in refractory moulds, sand castings [1]. Foundry sands are essential raw materials which are used in making moulds that accommodate molten metals during Foundry operations. They are used to make moulds, refractory coatings and cores, and in each of these applications, sand grains are sometimes combined with binding agents, additives, and water, to enhance certain properties [2-4]. Sands used in Foundry are of two major types namely silica and non-silica sands [5]. Most River sands because of their high silicon dioxide $\left(\mathrm{SiO}_{2}\right)$ content fall within the category of silica sand [6]. River sand, usually silica sand, is less expensive when compared to other Foundry sand, such as, zircon, chromite, and olivine sand. Based on their origin, river sands vary in shape, grain size, composition, and distribution pattern. The sands are naturally occurring deposits formed due to weathering and erosion of quartz-bearing igneous, metamorphic, and sedimentary rocks [7]. The products generated from these processes are subsequently transported to the site of deposition. The sand grains vary in size from a few micrometers to a few millimeters. Shape of sand grains may be round, sub-angular, angular, and very angular. The size and shape of these sand grains greatly affect the properties of moulding sand [5]. According to Handerson [8], medium-grade silica sands are used predominantly for casting steel and heavy grey ductile iron; while fine-grade silica sand is used in making high dimensionally accurate (precision) castings.

In the quest for discovering more deposits of sand that is suitable for foundry use, Nigerian researchers have made great contributions in the investigation of River sand deposits. 
Sheidi and Ajuwa [9] investigated the properties of River Niger sand in Bacita location, Nigeria, and found out that the River sand is suitable for production of quality casting of various metal alloys. Ayoola et al. [10] carried out an assessment on the suitability of Osun River sand deposit in Oshogbo, Nigeria, and discovered that the River sand is a naturally bonded Foundry sand. Bala and Khan [11] investigated the bulk properties of Warri, Ethiope, and Ughelli River sand in the middle belt of Nigeria. Results of their findings showed that sand from the three Rivers possess acceptable range of grain sizes [12], angular grain shape, and moderate permeability to produce good castings. Ayoola et al. [13] carried out a comparative analysis on Foundry properties of Osun and Saki River sand. They recommended, from the outcome of their findings, that River Osun has the demonstrable Foundry sand desired properties. Guma [14] studied the characteristics of Kaduna River sand in Northern Nigeria, and found out that the River sand could be easily controlled to obtain Foundry requirements for casting different types of metals.

The major source of Foundry sand in Osun State, Nigeria is River Osun. There has been massive depletion of this raw material from the River due to its continuous mining by jobbing and captive Foundries in the locality. Instead of importing synthetic sand for Foundry use, which is not cost friendly, this study was embarked upon to unravel the usability of Isasa River sand in the same geographical location for Foundry purpose. This paper characterized Isasa river sand that is situated at Gbongan, a town in Osun State, Southwest of Nigeria to determine the properties useful for foundry activities.

\section{Methodology}

The sand investigated in this work for Foundry use was collected from Isasa River at Gbongan town of geographical coordinate of latitude $7^{\circ} 28^{\prime} 38.42^{\prime}$ ' North and longitude $4^{\circ} 21^{\prime}$ ' $12^{\prime}$ " East, in Osun State, Nigeria. The sand sample was characterized to determine its suitability in the Foundry industry. Equipment used are laboratory digital balance, oven, trinocular microscope, Tandem pelletron electrostatic accelerator, sand washer, mechanical sieve shaker, and box furnace.

\subsection{Characterization of the River sand}

Properties of the River sand investigated are moisture content, grain shape, chemical composition, clay content, grain size and distribution, and sintering point. The investigations were carried out according to American Foundrymen Standard (AFS) experimental procedure.

\subsection{Moisture content}

Fifty (50) grams of sand sample collected was weighed with the aid of a laboratory digital balance and dried in oven at $110^{\circ} \mathrm{C}$ for one hour. It was then removed, cooled to room temperature, and weighed again. This process was repeated until a constant weight was attained. The test was replicated and average value was recorded for each sand sample. The ratio of loss of weight for each sand sample on heating and that of the sample before heating, expressed in percentage, gives the moisture content of the sand on wet bases. Moisture content is expressed mathematically as:

$$
\text { Moisture content }(\%)=\frac{W_{1}-W_{2}}{W_{1}} \times 100
$$


Where, $W_{1}$ is the weight of moist sample, and $W_{2}$ is the weight of sample after drying.

\subsection{Grain Shape}

The sand samples were examined using an Accu-scope 3001 LED trinocular microscope with 3.3MP CMOS digital camera to determine the shape of the sand grains.

\subsection{Chemical composition}

Chemical composition of the sand sample was determined by NEC 5SDH 1.7 MV Tandem pelletron electrostatic accelerator, a heavy ion accelerator system that is equipped with charge exchange ion source. The sand sample was initially milled to powder with the aid of a ring mill, and then pelletized to disc shapes with the aid of a hydraulic press and pelletizing accessories. The electrostatic accelerator was finally used to deliver well-focused $\mathrm{MeV}$ ion beams with high energy resolution to the prepared specimens. Compositions of the sand sample and plot were obtained from the control screen of the accelerator.

\subsection{Clay content}

Hundred (100) grams of the sand sample was initially dried to a constant weight at $110^{\circ} \mathrm{C}$ in the oven for an hour. Then, fifty (50) grams of sand was measured out of the dried sample with a digital balance and transferred to the wash beaker of sand washer. $475 \mathrm{ml}$ of distilled water and $25 \mathrm{ml}$ of $1.5 \%$ Tetra sodium pyrophosphate solution were added to the sample inside the wash beaker. The mixture was agitated by the stirrer unit for 5 minutes in the sand washer, after which water was added up to the mark on the bottle. The mixture was stirred again for two minutes and the content allowed settling for 10 minutes, after which the unclean water was siphoned off up to the $125 \mathrm{~mm}$ level from the base of the bottle. This procedure was repeated until the water became clear in the bottle. The wet sand was now transferred from the wash bottle and dried in the oven at $110^{\circ} \mathrm{C}$ to a constant weight at an hour interval, to completely remove moisture. The ratio of the loss of weight in the sand sample on heating and that of the washed sand sample, expressed in percentage, gives the clay content.

$$
\text { Clay content }(\%)=\frac{W_{a}-W_{b}}{W_{a}} \times 100
$$

$\mathrm{W}_{\mathrm{a}}$ is the initial weight of dried sample before washing, and $\mathrm{W}_{\mathrm{b}}$ is the final weight of dried sample after washing.

\subsection{Grain size and distribution}

Grain size and distribution of samples were determined using sieve analysis, and mechanical sieve shaker was employed for the experiment. Fifty (50) grams of clay-free sand samples were sifted through standard set of sieves for 15 minutes, starting with the coarse sieve, with the sieve shaker. Sand retained on each sieve and pan was weighed individually using a digital scale. The weight of sand retained on each sieve was expressed as the percentage of the total mass of sand. The result of each ratio was then multiplied by the corresponding sieve number weighting factor, usually called multiplier. Grain Fineness Number, representing grain size, is the summation of all products divided by the total percentage retained. GFN can be expressed as:

$$
G F N=\frac{\sum_{i}^{n} f_{i} W_{i}}{\sum_{i}^{n} W_{i}}
$$


Where, $i$ represents $1,2, \ldots$, n. $f_{i}$ is the weighting factor for each corresponding sieve, and $W_{i}$ is the percentage weight of sand collected on each sieve. Grain size distribution was obtained by plotting the weight of sand retained as a percentage of total mass of sample against the sieve number.

\subsection{Sintering point}

Fifty gram of the sand sample was held in a crucible plate and heated in a VBF $1200 \mathrm{X}$ box furnace for three minutes at a constant temperature, starting with $1000^{\circ} \mathrm{C}$ at an interval of $50^{\circ} \mathrm{C}$. After each heating, it was inspected if sintering had taken place at that particular temperature.

\section{Results and discussion}

Moisture content of Isasa River sand sample collected at Gbongan location is $4.30 \%$ and the clay content is $2.22 \%$, as presented in Table 1 . The results indicate that the River sand is unsuitable in its natural state for metal casting due to its low clay content, which may result in poor sand strength $[15,16]$.

Table 1: Results of moisture and clay contents of Isasa River sand

\begin{tabular}{lcccc}
\hline Property & $\begin{array}{c}\text { Initial Reading } \\
(\mathrm{g})\end{array}$ & $\begin{array}{c}\text { Final Reading } \\
(\mathrm{g})\end{array}$ & Average $(\mathrm{g})$ & Content $(\%)$ \\
\hline Moisture & 50 & 47.88 & 47.85 & 4.30 \\
Content & & 47.82 & & \\
Clay Content & 50 & 48.91 & 48.89 & 2.22 \\
& 50 & 48.87 & & \\
\hline
\end{tabular}

Result obtained from sieve analysis of the sand sample from the location under study, presented in Table 2, showed that the River sand has grains with AFS grain fineness number of 49. This number classifies it under coarse grain size, which is still within the acceptable range of foundry sand and suitable for foundry application [5, 17]. This type of sand possesses high permeability and refractoriness $[18,19]$. Variation in percentage of sand retained with sieve and grain distribution for the sand sample is presented in Figure 1. The River sand can be classified as 4- screen sand and the highest percentage of sand retained falls on the screen corresponding to sieve number 50 .

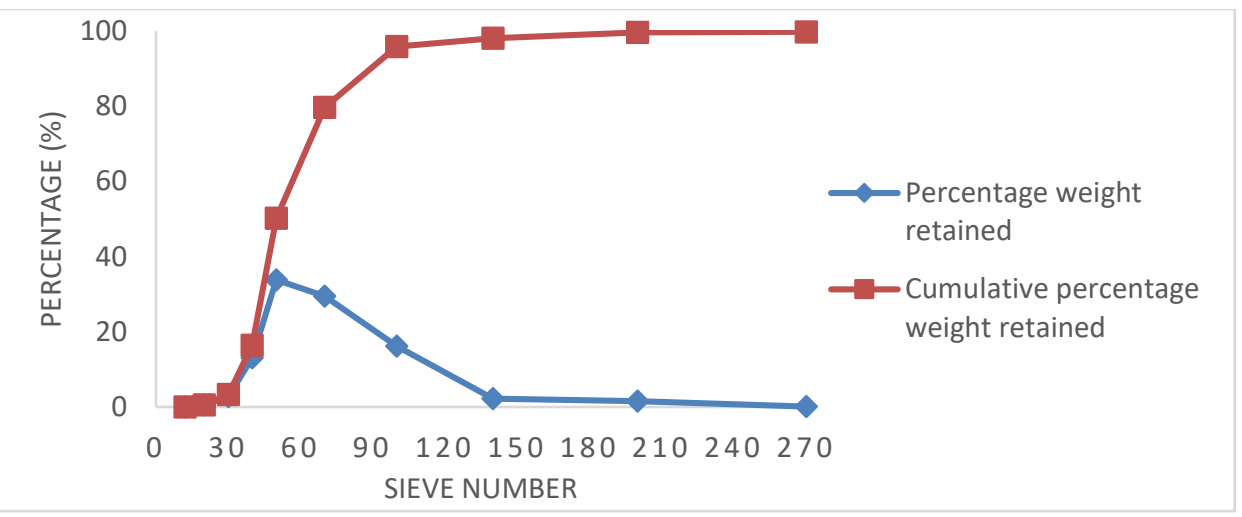

Figure 1: Graph of Isasa river sand grain size distribution 
Table 2: AFS Sieve Analysis of Isasa River sand sample

\begin{tabular}{ccccccccc}
\hline $\begin{array}{l}\text { Sieve } \\
\text { No }\end{array}$ & $\begin{array}{l}\text { Aperture } \\
\text { size } \\
(\mu \mathrm{m})\end{array}$ & $\begin{array}{l}\text { Sieve } \\
\text { Weght }(\mathrm{g})\end{array}$ & $\begin{array}{l}\text { Sieve }+ \\
\text { Sand } \\
\text { Weight } \\
(\mathrm{g})\end{array}$ & $\begin{array}{l}\text { Weight } \\
\text { retained } \\
(\mathrm{g})\end{array}$ & $\begin{array}{l}\text { Weight } \\
\text { retained } \\
(\%)\end{array}$ & $\begin{array}{l}\text { Cumulative } \\
\text { Weight } \\
\text { retained } \\
(\%)\end{array}$ & $\begin{array}{l}\text { Multiplying } \\
\text { Factor } \\
\left(f_{i}\right)\end{array}$ & Product \\
\hline 12 & 1651 & 451.52 & 451.52 & 0 & 0 & 0 & 5 & 0 \\
20 & 833 & 375.04 & 375.32 & 0.28 & 0.56 & 0.56 & 10 & 5.6 \\
30 & 589 & 370.13 & 371.49 & 1.36 & 2.72 & 3.28 & 20 & 54.4 \\
40 & 414 & 353.75 & 360.31 & 6.56 & 13.12 & 16.4 & 30 & 393.6 \\
50 & 295 & 334.73 & 351.63 & 16.9 & 33.8 & 50.2 & 40 & 1352 \\
70 & 208 & 314.17 & 328.91 & 14.74 & 29.48 & 79.68 & 50 & 1474 \\
100 & 147 & 288.49 & 296.55 & 8.06 & 16.12 & 95.8 & 70 & 1128.4 \\
140 & 104 & 288.16 & 289.88 & 1.12 & 2.24 & 98.04 & 100 & 224 \\
200 & 74 & 287.79 & 288.56 & 0.77 & 1.54 & 99.58 & 145 & 223.3 \\
270 & 53 & 281.56 & 281.64 & 0.08 & 0.16 & 99.74 & 200 & 32 \\
Pan & 0 & 478.71 & 478.71 & 0 & 0 & 99.74 & 300 & 0 \\
& & & & 49.87 & 99.74 & & & 4887.3 \\
\hline
\end{tabular}

$$
\text { AFS GFN }=\frac{4887.30}{99.74}=49
$$

Microscopic examination of Isasa River sand shows that Isasa River sand comprises of angular grains with medium sphericity. Attributes of this type of grain shape are low permeability and high strength because of the grains interlocking tendency [17]. Figure 2 presents the elemental composition of the River sand sample in parts per million (ppm) obtained by Particle Induced X-ray Emission (PIXE) spectra of the Tandem accelerator, and Table 3 presents its chemical composition. Results obtained showed that Silicon ( $\mathrm{Si}$ ) is the predominant element and Silica $\left(\mathrm{SiO}_{2}\right)$ has the highest percentage by weight of all the elements and constituents discovered in the Isasa river sand sample. This is evidence that Isasa River sand is silica sand. These proportions are of acceptable standard [20] and put the sand in good stead for foundry use because the higher the proportion of $\mathrm{SiO}_{2}$, the better is the refractoriness and thermal stability of the sand [21]. Other constituents found in the sand, such as, $\mathrm{Al}_{2} \mathrm{O}_{3}, \mathrm{Fe}_{2} \mathrm{O} 3, \mathrm{TiO}_{2}$, and Akalis are in minute quantities while the rest are at trace level. Figure 3 showed the initial state of the River sand sample before and after sintering occurred. The sample sintered at temperature of $1400^{\circ} \mathrm{C}$. The high sintering point is attributed to the grain size and high silica content of the river sand. The sintering point possessed by this river sand makes it suitable, if combined with binders, for casting of non-ferrous metals and gray iron; and in the production of refractory coatings and cores [5].

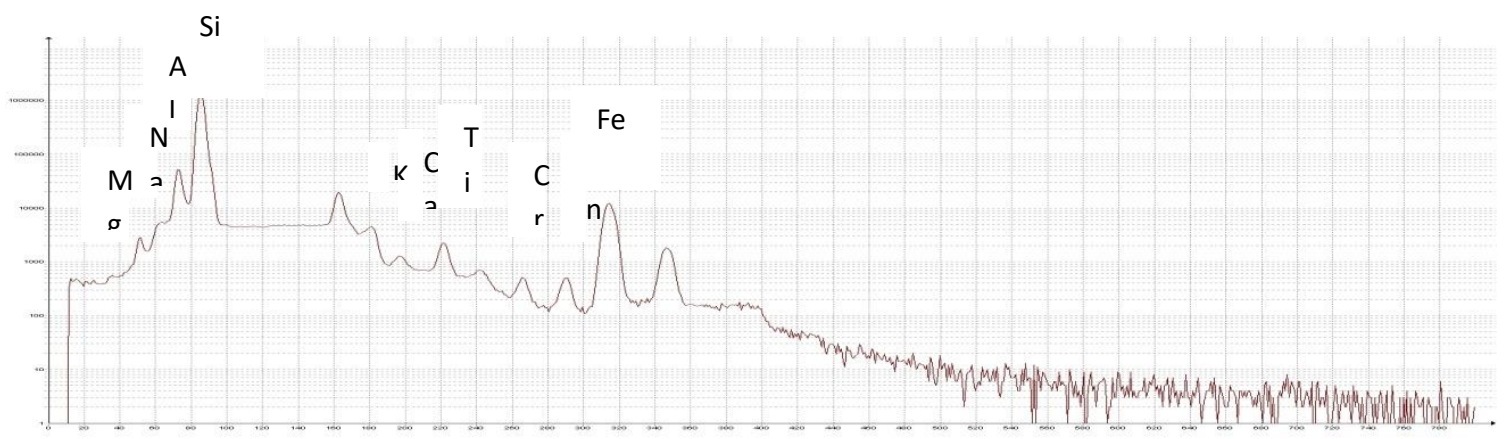

Figure 2: PIXE spectra of composition of Isasa river sand sample 
Table 3: Chemical composition of Isasa river sand

\begin{tabular}{lllllllll}
\hline Constituents & $\mathrm{SiO}_{2}$ & $\mathrm{Al}_{2} \mathrm{O}_{3}$ & $\mathrm{Fe}_{2} \mathrm{O}_{3}$ & $\mathrm{TiO}_{2}$ & $\mathrm{CaO}$ & $\mathrm{MgO}$ & $\mathrm{Na}_{2} \mathrm{O}$ & $\mathrm{K}_{2} \mathrm{O}$ \\
\hline \% Composition & 92.9952 & 2.9296 & 1.8337 & 1.2300 & 0.1297 & 0.1364 & 0.3332 & 0.5725 \\
\hline
\end{tabular}

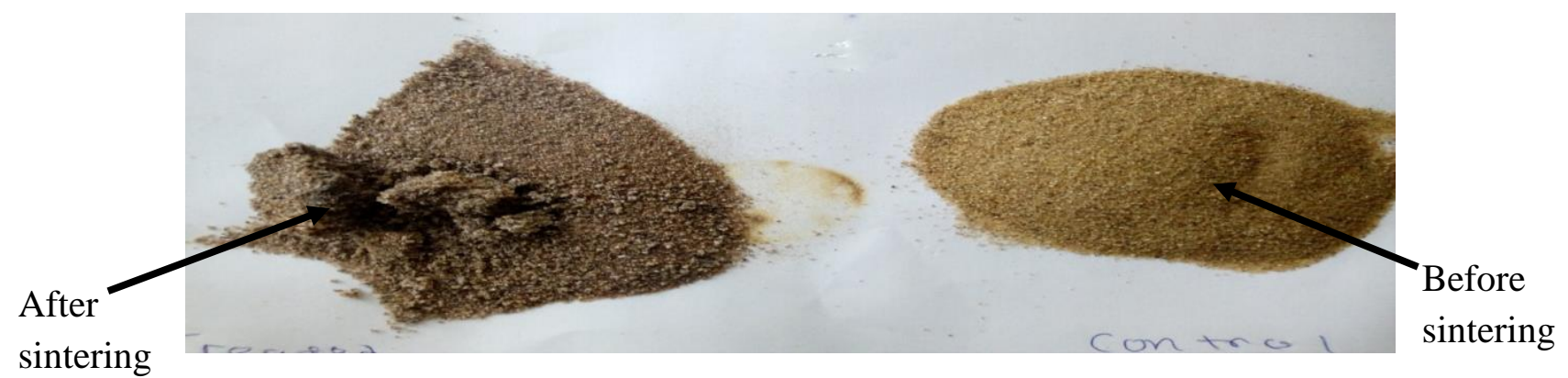

Figure 3: Isasa River sand samples

\section{Conclusion}

Investigation of the Foundry properties of Isasa River sand has been carried out. The River sand has coarse grains, high sintering point, hence high refractoriness, and angular grain shape that is attributed to good grain interlocking capability. It is a suitable raw material for refractory coating, when pulverized, and core making. However, it requires addition of binder to be utilized in the making of moulds for metal castings due to its low clay content.

\section{References}

[1] Adegbuyi P. A. O., Uhomoibhi, J. O., Foundry properties of backing sand: Some Engineering properties and improvement, Proceedings of International Conference on Engineering Education, Coimbra, Portugal, 2011, pp. 635-640

[2] Seidu, S.O., Effect of additives on some selected properties of Base Sand, Journal of Minerals and Materials characterization and Engineering, 2, 2014, pp. 507-512

[3] Paul, A., Effects of the moisture content on the foundry properties of Yola Natural sand, Leonardo Electronic Journal of Practices and Technologies, 2011, 19, pp.85-96

[4] Kenneth, E.R., Silica sand from south-central Kensas for foundry use. Kansas Geological survey, Bulletin 86, part 4. Retrieved from www.kss.ku.edu/Publications/Bulletins/86-4/index.html (Accessed 10th September 2017).

[5] Rao, P.N. (2001). Manufacturing Technology: Foundry, Forming and Welding. $2^{\text {nd }}$ Ed., Tata McGraw-Hill Publishing Company Limited, New Delhi, 2001

[6] Olawale, J.O., Ibitoye, S.A., and Shittu, M.D., Suitability Assessment of some Nigerian Natural Moulding sand Deposits for Foundry Use, Proceedings of Faculty of Technology Conference titled; "Innovative Technologies for socio-economic Transformation in Developing Countries", Obafemi Awolowo University, Ile-Ife, 2011, 35-39.

[7] Kotzin, E.L., Metal Casting and Molding Processes. American Foundrymen's Society, Inc., Des Plaines, Illinois, 1989

[8] Handerson, G.V., Foundry Sand, Industrial Minerals and Rocks. $5^{\text {th }}$ edition, New York: AIME, 1983, pp. 271-278

[9] Sheidi, H. M., Ajuwa, C. I., Investigation on properties of river sand for sound casting: River Niger, Bacita, Nigeria Journal of Engineering and Applied Sciences, 2008, 3(3), pp. 214-216 
[10] Ayoola, W.A., Adeosun, S.O., and Oladoye, A.M., Suitability of Oshogbo Sand Deposit as Moulding Sand. The Kenya Journal of Mechanical Engineering, 2010, 6(1), pp. 36-41

[11] Bala, K.C., and Khan, R.H., Characterization of Beach River Sand for Foundry Application. Leonardo Journal of Sciences, 2013, 23, pp. 1-6

[12] Dietert, H.W., and Graham, A. L., Sand Control Program that saves. AFS Transactions, 1974, 82:181-188

[13] Ayoola, W. A., Oyetunji, A., Adeosun, S. O., Sekunowo, O. I., Bodude, M. O., Investigation of Foundry properties of Oshogbo and Saki Silica sand deposits, Daffodil International University Journal of Science and Technology, 2013, vol 8(2), pp. 11-17

[14] Guma, T. N., Characteristic Foundry Properties of Kaduna River Sand, International Journal of Engineering and Science, 2012, vol 1(11), pp. 03-08

[15] Mikhailov, A.M., Metal Casting. Revised Edition, Mir Publishers, Moscow, USSR, 1989

[16] Sharma, P.C., A Textbook of Production Technology (Manufacturing Processes), S. Chand and Company Ltd, New Delhi, 2008

[17] Brown, J.R.,Foseco Foundryman's Handbook, Tenth Edition, Butterworth Heinman Publishers, Oxford, 1994, 16-17.

[18] Jain, R.K., Production Technology. $16^{\text {th }}$ Edition, Khanna Publishers, Delhi., 2008

[19] Adesina, A.S. and Adegbite, Engineering characterization of Tsaragi River Sand for moulding in Foundry work, Journal of Research and Development, 2013, Vol 5(1), pp 20-27.

[20] Beeley, P., The Moulding materials: Properties, Preparation and Testing, Foundry Technology, Butterworth-Heinemann, 2nd Edition, 2001, pp. 178-443

[21] Heine, R.W., Loper, C.R., and Rosenthal, P., Principles of Metal Casting, Tata McGraw-Hill Publishing Company Limited, New Delhi, 2001 